\title{
Improvement of Micronutrient Content in Health Drink Powder with Incorporation of Encapsulated Carrot Coagulum Powder
}

\author{
Snehal Giri* and Neena Joshi \\ Department of Food Science and Nutrition, University of Agricultural Sciences, \\ Bangalore, India \\ *Corresponding author
}

Keywords

Encapsulated carrot coagulum powder, Spray drying, Germinated flours, Skimmed milk powder, Malting, Health drink powder, Total carotenoid content

Article Info

Accepted:

18 November 2020 Available Online:

10 December 2020

\begin{abstract}
A B S T R A C T
Carrot out-grades were used for the production of enzymatic extracted carrot coagulum to utilise the waste generated while grading the carrots. Spray drying technique was used to prepare the encapsulated carrot coagulum powder (ECCP) from enzyme extracted carrot coagulum at an inlet temperature of $170{ }^{\circ} \mathrm{C}$ and using $15 \%$ of maltodextrin as carrier agent. The obtained powder was incorporated in different proportions in the formulation of health drink powder (HDP). Ingredients used were malted wheat, malted green gram, soy protein isolate, malt extract and skimmed milk powder (SMP). The developed product contained 2.5, 5, 7.5 and 10\% ECCP. A 9-point hedonic sensory score card was used for studying the acceptability. Sensory evaluation indicated that addition of up to $7.5 \% \mathrm{ECCP}$ into the formulation of HDP improved its appearance, colour and overall acceptability. This formulation was then selected for the analysis of proximate, minerals, total carotene and water activity. HDP without the addition of ECCP served as control. ECCP incorporated HDP had lower water activity and moisture compared to control health drink powder. Nutritional analysis of HDP with $7.5 \%$ incorporation of ECCP resulted in a significant increase in the fibre, carbohydrate, energy and also minerals such as potassium, zinc, iron, sulphur, copper and sodium. Incorporation of ECCP resulted in a higher total carotenoid content $(1.24 \mathrm{mg} / 100 \mathrm{~g})$ compared to control $(0.65 \mathrm{mg} / 100 \mathrm{~g})$. Addition of $15 \mathrm{~g}$ of HDP in $100 \mathrm{ml}$ of milk (corresponding to one serving) provides energy $125 \mathrm{kcal}$, protein $6.18 \mathrm{~g}$, calcium $122.79 \mathrm{mg}$ and total carotene $0.186 \mathrm{mg}$. In conclusion, ECCP can be used in the formulation of HDP to improve the nutritional quality without affecting the product sensory quality.
\end{abstract}

\section{Introduction}

Carrot (Daucus carota L.) is the most important crop of Apiaceae family. It is one of the most popular root crops grown throughout the world. It is important source of dietary carotenoids mainly for high $\beta$ carotene, which is a lipid soluble carotenoid having high vitamin A activity (Biesalski, 1997). It has a typical chemical structure, consisting of a polyene chain with 11 conjugated double bonds and $\beta$-ring at each end of the chain (Augspole et al., 2014). The total carotenoids content in the edible portion of carrot roots range from 6,000 to 54,800 $\mu \mathrm{g} / 100 \mathrm{~g}$ (Simon and Wolff, 1987). Carrot in 
primary production is rejected for many reasons from field to packinghouse. Most of the time the carrot out-grades are rejected purely for aesthetic/cosmetic reasons; not meeting the retailer standards based on their shape or size. Nutritional content in these edible out-grades are on par with regular carrot (Kasale et al., 2019). So far, the carrot out-grades, do not find proper utilization. Hence, in the present study the noncommercial carrots out-grades were utilized.

With little effort fruits and vegetables can be converted into valuable products which make them accessible throughout the year. This can help to mitigate micronutrient deficiencies (Gustavsson et al., 2011; Keding et al., 2013). The most common method for preservation of fruits and vegetables is the dehydration method. Dried products can be easily applied to various food products to improve colour and flavour (Jiang and Adhikari, 2013) and to enhance the nutritional value and provide the human body with additional health-related constituents. Appropriate processing at the time of gluts, can be profitable besides making available the nutrients to the poor Indian dietaries. A very effective method in which liquid products are directly turned into fine powder is spray drying.

This process is applied broadly in industry, especially for processing dairy and fruit and vegetable products (Alamilla-Beltran et al., 2005). Spray drying preserves fruit and vegetable juices in powder form. It enhances the nutritional and physical properties of obtained products (Verma and Singh, 2015).Encapsulation using spray drying technique is an efficient method for the preservation of natural colorants, flavors, bioactive compounds by entrapping the ingredient in a coating with the help of carrier agents Maltodextrin is common drying aids for encapsulation (Ersus and Yurdagel, 2007). Carrot powder has utility as an ingredient in various nutritional and health promoting value-added food products like formulated drinks, health drinks, beverage powders, baby foods and other products such as instant soups or meals etc which can augment nutritional security. Health drinks are popular among adults and children. These are widely consumed as taste enhancers to encourage drinking of milk among growing children (Farzana et al., 2017). Nowadays health drinks are gaining popularity among the health-conscious society also (Abrams et al., 2003). So, health drinks could be a good target for incorporation of carrot powder. Malting of cereals and legumes is a traditional process and possess nutritional benefits. In the malting process, starch is hydrolysed to reducing sugar by hydrolytic enzymes which when added to liquid food products can reduce the dietary bulk and increase the calorie intake. Malting of grains improves the organoleptic and nutritional properties (Griffith et al., 1993). These are usually the base for health drink formulations.

The present research work was aimed to formulate health drink powder using germinated and mashed wheat and greengram flour along with soy protein isolate, malt extract and skimmed milk powder. Health drink powder incorporated with different levels of encapsulated carrot coagulum powder was developed and evaluated for sensory and nutritional properties.

\section{Materials and Methods}

\section{Raw materials}

Carrot out-grades were procured from Yelahanka local market, Bangalore. Pectinase (Pectinex Ultra SPL) and cellulase (Celluclast 1.5L) enzymes were procured from Novozymes, Bangalore. For the development of HDP, raw materials such as food grade citric acid, wheat, green gram, soy protein 
isolate, malt extract, skim milk powder, were purchased from the local market of Bangalore, India.

\section{Preparation of encapsulated carrot coagulum powder}

The process for the production of encapsulated carrot coagulum powder, using spray drier, is presented in the Figure 1. Carrot out-grades were used for the preparation of enzymatically extracted carrot coagulum. Enzymatic extraction of carrot coagulum from carrot out-grades was followed according to the procedures outlined byWagner and Warthesen, 1995; Stoll et al., 2003; Darshan, 2015 with modification. Pectinase and cellulase enzymes were used in the concentration of $0.02 \%$ for the enzymatic extraction. Enzymatic extracted carrot coagulum thus obtained was used for spray drying (Lab spray dryer, LSD-48, JISL, Mumbai). Maltodextrin DE 20 in $15 \%$ concentration was then added to carrot coagulum and volume was made up to $100 \mathrm{ml}$. Encapsulation of spray drying was carried out at the constant aspirator rate of $90 \%$, feed pump $12 \%$ and at pressure $1.5-2.0 \mathrm{~kg} \mathrm{~cm}^{-2}$. The spray dryer operated at inlet temperature of $170{ }^{\circ} \mathrm{C}$ and outlet temperatures maintained at $86 \pm 5{ }^{\circ} \mathrm{C}$. After the encapsulation process the powder was collected and packed in high density polyethylene bags and stored in airtight container containing silica gel.

\section{Preparation of germinated of wheat and green gram flour}

Wheat and green-gram grains were cleaned and separately washed with clean water, soaked in water overnight, then tied in muslin cloth and maintained at room temperature for 24-48 hours. The germinated wheat and green gram were then air dried in hot air oven at 50 ${ }^{\circ} \mathrm{C}$. The dried germinated grains were milled to get fine flour and flours were further sieved to get fine particles. Wheat and green gram flours were mixed with water in a ratio of $1: 3$ and 1:5, cooked for 20 minutes and obtained slurries werekept in an oven at around $65^{\circ} \mathrm{C}$, separately according to method described by Farzana et al., (2017). The dried slurry was then milled into a fine powder. All the flours were packed into high density polyethylene bags and stored in refrigerator at $4{ }^{\circ} \mathrm{C}$ to avoid spoilage and further for formulation of HDP.

\section{Formulation of health drink powder}

The obtained wheat flour and green gram powder was mixed with malt extract and soy protein isolate. All these were thoroughly mixed to ensure proper mixing. Skimmed milk powder and encapsulated carrot coagulum powder were then added at different proportions (Table 1). The developed product contained 2.5, 5, 7.5 and $10 \%$ ECCP. The prepared health drink powder was sealed in polyethylene packets, stored at $4{ }^{\circ} \mathrm{C}$ in a refrigerator and evaluated for sensory scores within 24 hours. The process for formulation of the health drink powder is shown Figure 2.

\section{Sensory analysis}

Developed HDP with and without ECCP $(15 \mathrm{~g})$ was mixed with $100 \mathrm{ml}$ of warm milk and was evaluated by 21 semi trained panel members using a 9-point hedonic scale (Murray et al., 2001).A nine-point hedonic scale where $1=$ (dislike extremely), $2=$ (Dislike very much), $3=$ (Dislike moderately), $4=$ (Dislike slightly), $5=$ (neither like nor dislike), $6=$ (like slightly), $7=$ (like moderately), $8=$ (like very much) and $9=$ (like extremely) was used.

Based on sensory evaluation best accepted variation of HDP $\left(\mathrm{T}_{3}\right)$ along with a control HDP was analyzed for total carotenoid content, water activity, proximate and mineral composition. 


\section{Estimation of total carotenoid content}

Total carotenoids of carrot coagulum powders were analysed by the method described by Ranganna (1986). About $2 \mathrm{~g}$ sample was mixed with $5 \mathrm{~mL}$ acetone. The mixture was shaken on vortex for $10 \mathrm{~min}$. The filtrate was poured in separating funnel and $15 \mathrm{ml}$ of petroleum ether was added and then washed repeatedly with distilled water. Filter paper (Whatman No. 1) covered with anhydrous sodium sulfate (10 g) was used to remove residual water. The extract volume was adjusted to $25 \mathrm{ml}$ using petroleum ether containing $3 \%$ of acetone followed by absorbance estimation at $452 \mathrm{~nm}$ using spectrophotometer.

\section{Water activity}

Water activity (aw values) of HDP was measured by using a water activity meter (Rotronic, Hygrolab).

\section{Proximate and mineral estimation of developed HDP}

Proximate composition (i.e., moisture, ash, protein, fat, fiber) of developed HDP with and without ECCP were estimated using AOAC (2005) methods. The carbohydrate content was determined by the difference method and the energy value was determined by multiplying the proportion of protein, fat, and carbohydrate by their respective physiological energy values and taking the sum of the products (Eneche, 1999). Minerals in the samples were determined using AOAC (2005) methods. The concentrations of $\mathrm{Ca}, \mathrm{Mg}, \mathrm{P}, \mathrm{Zn}$ and $\mathrm{Fe}$ were determined using Atomic Absorption Spectrometer. $\mathrm{K}$ and $\mathrm{N}$ were measured using flame photometer and results expressed in $\mathrm{mg} / 100 \mathrm{~g}$.

\section{Statistical analysis}

All analysis was worked in triplicates, with the exception of the sensory evaluation. Data was expressed as mean and standard deviation and non-parametric test were used for the sensory data and t-test was used to ascertain statistical differences at $95 \%$ confidence interval for proximate and mineral estimation.

\section{Results and Discussion}

\section{Sensory evaluation of health drink powder}

Sensory evaluation is a critical factor that needs to be considered for evaluating the ability of ingredients to fortify food formulations and the acceptability of final products by consumers. Sensory evaluation scores for health drink powder (15 g) mixed with warm milk $(100 \mathrm{ml})$ are presented in Figure 3 and Table 2.

There were no significant differences for the variables such as texture, flavor and taste. However significant differences existed for appearance, colour, and overall acceptability between the samples of HDP with and without ECCP. The scores for appearance ranged from 8.11 to 8.50 , color 8.33 to 8.77 , texture 8.11 to 8.22 , flavor 7.94 to 8.33 , taste 7.88 to 8.50 and overall acceptability 7.33 to 8.44. Among the sensory indicators, color is the first indicator reflecting the quality of a product that attracts consumer's attention. Sensory score for appearance and color of health drink powder significantly increased as the percentage of incorporation of ECCP increased. Taste and flavor of the product scored was good at $7.5 \%$ level of carrot powder incorporation. Previous workers have also suggested this. Addition of $1.5 \%$ of encapsulated eggplant extract into the formulation of gummy candy improved its color and overall acceptability (Sarabandi et al., 2019).

Among five variations of HDP, sensory evaluation scores for overall acceptability showed that $\mathrm{T}_{3}$ (8.33) was best accepted followed by $\mathrm{T}_{2}$ (8.27), $\mathrm{T}_{1}$ (7.94), and $\mathrm{T}_{4}$ (7.33) 
and $\mathrm{T}_{0}$ control (8.44) scored highest. Same is depicted in Fig. 3. Health drink powder with $7.5 \%$ level of incorporation of ECCP was on par with the control for sensory acceptability.
Thus, health drink powder containing $7.5 \%$ level of incorporation was selected for further study.

Table.1 Composition of different combinations of health drink powder

\begin{tabular}{|l|c|c|c|c|c|}
\hline \multirow{2}{*}{ Ingredients } & \multicolumn{5}{|c|}{ Amount (\%) } \\
\cline { 2 - 6 } & $\mathbf{T}_{\mathbf{0}}$ & $\mathbf{T}_{\mathbf{1}}$ & $\mathbf{T}_{\mathbf{2}}$ & $\mathbf{T}_{\mathbf{3}}$ & $\mathbf{T}_{\mathbf{4}}$ \\
\hline Germinated wheat flour & 20 & 20 & 20 & 20 & 20 \\
\hline Germinated Green gram & 20 & 20 & 20 & 20 & 20 \\
\hline Malt extract & 20 & 20 & 20 & 20 & 20 \\
\hline Soy protein isolate & 10 & 10 & 10 & 10 & 10 \\
\hline Spray dried carrot powder & 0 & 2.5 & 5 & 7.5 & 10 \\
\hline Skimmed milk powder & 30 & 27.5 & 25 & 22.5 & 20 \\
\hline Total & $\mathbf{1 0 0}$ & $\mathbf{1 0 0}$ & $\mathbf{1 0 0}$ & $\mathbf{1 0 0}$ & $\mathbf{1 0 0}$ \\
\hline
\end{tabular}

$\mathrm{T}_{0^{-}}$Control

$\mathrm{T}_{1}-2.5 \%$ carrot coagulum powder incorporated HDP

$\mathrm{T}_{2}-5 \%$ carrot coagulum powder incorporated HDP

$\mathrm{T}_{3}-7.5 \%$ carrot coagulum powder incorporated HDP

$\mathrm{T}_{4}-10 \%$ carrot coagulum powder incorporated HDP

Table.2 Mean sensory scores of developed health drink powders

\begin{tabular}{|c|c|c|c|c|c|c|}
\hline $\begin{array}{l}\text { Level of ECCP } \\
\text { Incorporation }\end{array}$ & Appearance & Colour & Texture & Flavour & Taste & $\begin{array}{c}\text { Overall } \\
\text { acceptability }\end{array}$ \\
\hline Control $\left(\mathbf{T}_{\mathbf{0}}\right)$ & 8.11 & 8.33 & 8.22 & 8.33 & 8.50 & 8.44 \\
\hline $2.5 \%\left(\mathrm{~T}_{1}\right)$ & 8.22 & 8.44 & 8.22 & 8.11 & 8.27 & 7.94 \\
\hline $5.0 \%\left(\mathrm{~T}_{2}\right)$ & 8.38 & 8.50 & 8.16 & 8.11 & 8.11 & 8.27 \\
\hline $7.5 \%\left(\mathrm{~T}_{3}\right)$ & 8.44 & 8.61 & 8.11 & 8.30 & 8.38 & 8.33 \\
\hline $10 \%\left(\mathrm{~T}_{4}\right)$ & 8.50 & 8.77 & 8.16 & 7.94 & 7.88 & 7.33 \\
\hline F value & $*$ & $*$ & NS & NS & NS & $*$ \\
\hline SEm \pm & 0.200 & 0.202 & 0.150 & 0.261 & 0.202 & 0.232 \\
\hline CD@5\% & 0.405 & 0.408 & 0.305 & 0.528 & 0.410 & 0.470 \\
\hline
\end{tabular}

*Significant at $5 \%$

\# $\mathrm{T}_{0^{-}}$Control

$\mathrm{T}_{1}-2.5 \%$ carrot coagulum powder incorporated HDP

$\mathrm{T}_{2}-5 \%$ carrot coagulum powder incorporated HDP

$\mathrm{T}_{3}-7.5 \%$ carrot coagulum powder incorporated HDP

$\mathrm{T}_{4}-10 \%$ carrot coagulum powder incorporated HDP 
Table.3 Proximate composition, total carotenoid content (per 100g) and water activity of health drink powders (HDPs) with and without ECCP incorporation

\begin{tabular}{|l|l|l|l|}
\hline & HDP T $_{\mathbf{0}}^{\#}$ & HDP T $_{\mathbf{3}}^{\#}$ & t-test \\
\hline Moisture (g) & $5.86 \pm 0.03$ & $5.57 \pm 0.06$ & $12.59^{* *}$ \\
\hline Protein (g) & $22.06 \pm 0.11$ & $19.91 \pm 0.135$ & $25.33^{* *}$ \\
\hline Fat (g) & $5.06 \pm 0.16$ & $5.17 \pm 0.075$ & $1.37^{\mathrm{NS}}$ \\
\hline Crude fiber (g) & $0.6 \pm 0.03$ & $0.7 \pm 0.03$ & $6.32^{*}$ \\
\hline Ash (g) & $3.49 \pm 0.050$ & $3.04 \pm 0.06$ & $3.93^{*}$ \\
\hline Carbohydrate (g) & $62.95 \pm 0.36$ & $65.50 \pm 0.10$ & $48.75^{* *}$ \\
\hline Energy (Kcal) & $387.02 \pm 0.60$ & $387.87 \pm 0.260$ & $3.16^{\mathrm{NS}}$ \\
\hline Total carotenoid content (mg) & $0.60 \pm 0.07$ & $1.24 \pm 0.04$ & $12.83^{* *}$ \\
\hline Water activity & $0.45 \pm 0.08$ & $0.44 \pm 0.03$ & $1.75^{*}$ \\
\hline
\end{tabular}

Mean \pm Standard deviation

\# HDP T $_{0^{-}}$Control

HDP $\mathrm{T}_{3}-7.5 \%$ carrot coagulum incorporated HDP

Table.4 Mineral composition (mg/100g) of health drink powder

\begin{tabular}{|l|l|l|l|}
\hline & HDPT $_{\mathbf{0}}^{\#}$ & HDPT $_{\mathbf{3}}^{\#}$ & t-test \\
\hline Phosphorus & $28.65 \pm 0.66$ & $26.85 \pm 0.40$ & $11.38^{* *}$ \\
\hline Potassium & $212 \pm 5.03$ & $301.7 \pm 1.02$ & $44.35^{* *}$ \\
\hline Calcium & $24.25 \pm 0.47$ & $18.6 \pm 0.65$ & $9.38^{* *}$ \\
\hline Magnesium & $81.25 \pm 0.60$ & $58.5 \pm 0.80$ & $40.69^{* *}$ \\
\hline Sulphur & $1.9 \pm 0.15$ & $2.85 \pm 0.10$ & $8.49^{* *}$ \\
\hline Zinc & $0.955 \pm 0.60$ & $1.31 \pm 0.05$ & $31.75^{* *}$ \\
\hline Copper & $1.1 \pm 0.15$ & $1.425 \pm 0.60$ & $3.15^{*}$ \\
\hline Iron & $37.68 \pm 0.57$ & $41.47 \pm 0.35$ & $11.84^{* *}$ \\
\hline Manganese & $3.1 \pm 0.32$ & $2.1 \pm 0.15$ & $7.07^{* *}$ \\
\hline Sodium & $0.346 \pm 0.02$ & $1.027 \pm 0.05$ & $253.10^{* *}$ \\
\hline
\end{tabular}

* Mean \pm Standard deviation

\# HDP $\mathrm{T}_{0}$ - Control

$\mathrm{HDP}_{3}-7.5 \%$ carrot coagulum incorporated HDP 
Fig.1 Flow chart for the development of encapsulated carrot coagulum powders

\section{Carrot qut-grades}

Cleaning and cutting into small pieces

Blanching carrots at $80{ }^{\circ} \mathrm{C}$ for $7 \mathrm{~min}$ in 2 parts $(1: 2)$ of boiling water $(0.2 \%$ citric acid)

Grinding of carrot along with blanching water using domestic grinder

Juice extraction through muslin cloth

Addition of pectinase $(0.02 \%)$ and cellulase $(0.02 \%)$ and kept in dark condition at $\mathrm{O}^{\circ} \mathrm{C}$ for 4 hours for sedimentation

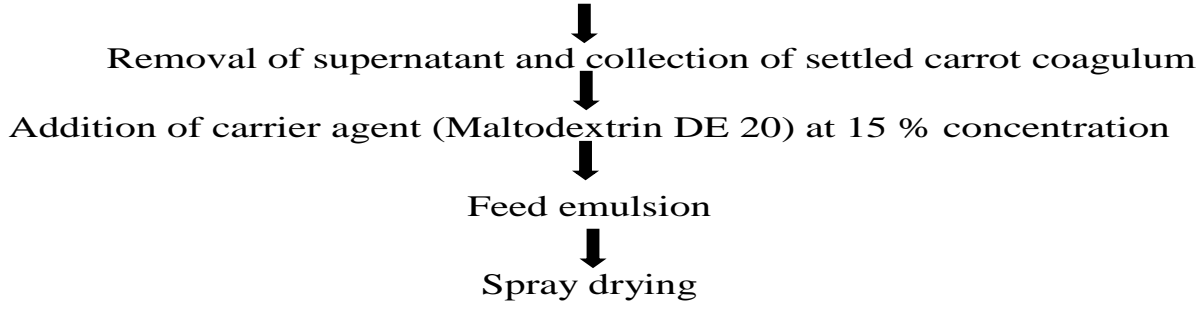

(Inlet air temperature: $170{ }^{\circ} \mathrm{C}$, Feed pump: 12\%, Aspirator rate - 90\%, Pressure -1.5-2.0 $\mathrm{kg} / \mathrm{cm}^{2}$ )

Collection of encapsulated carrot coagulum powder

Packing in AP pouches

Fig.2 Flow chart for the formulation of health drink powder

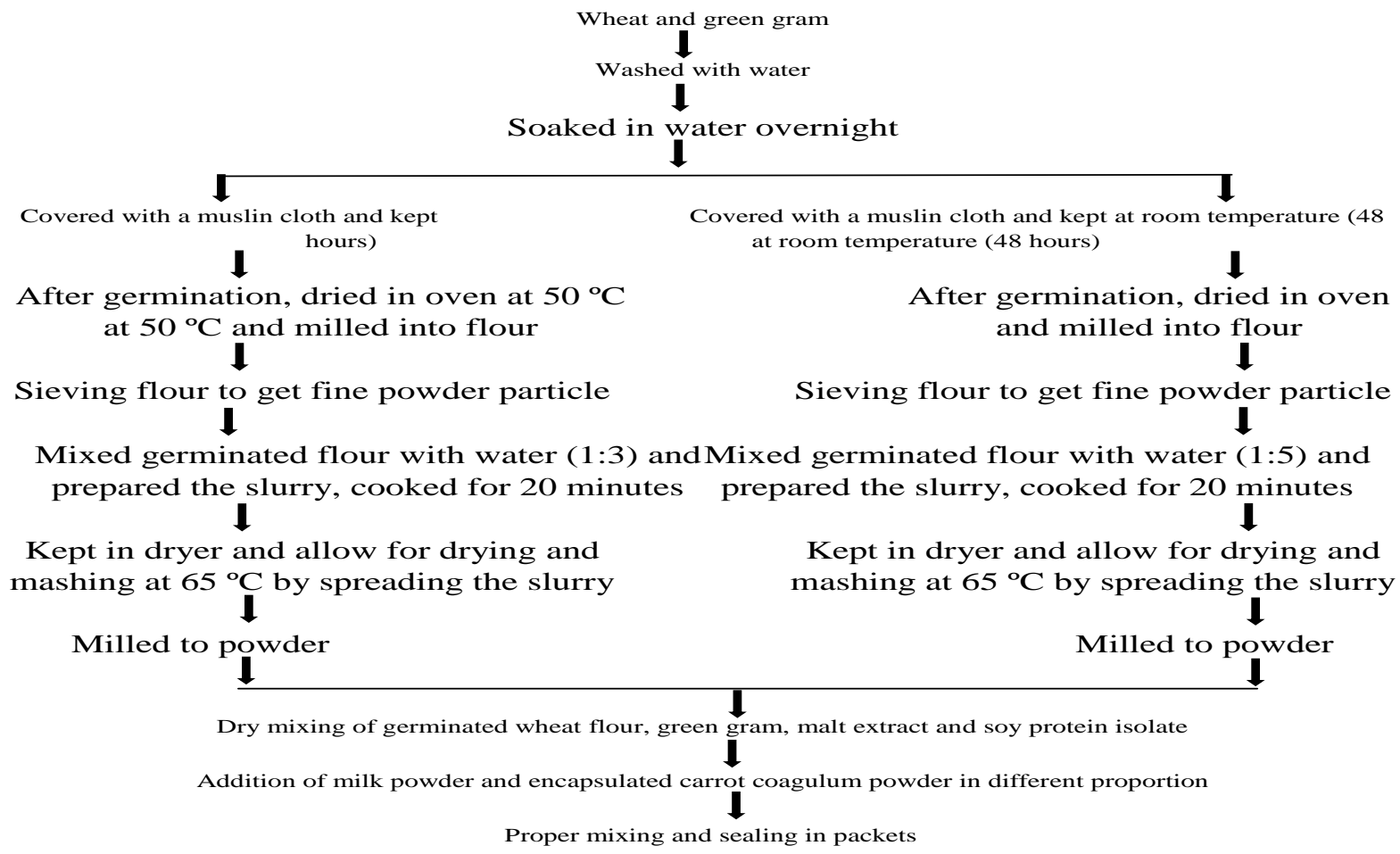


Fig.3 Mean sensory scores of developed health drink powders

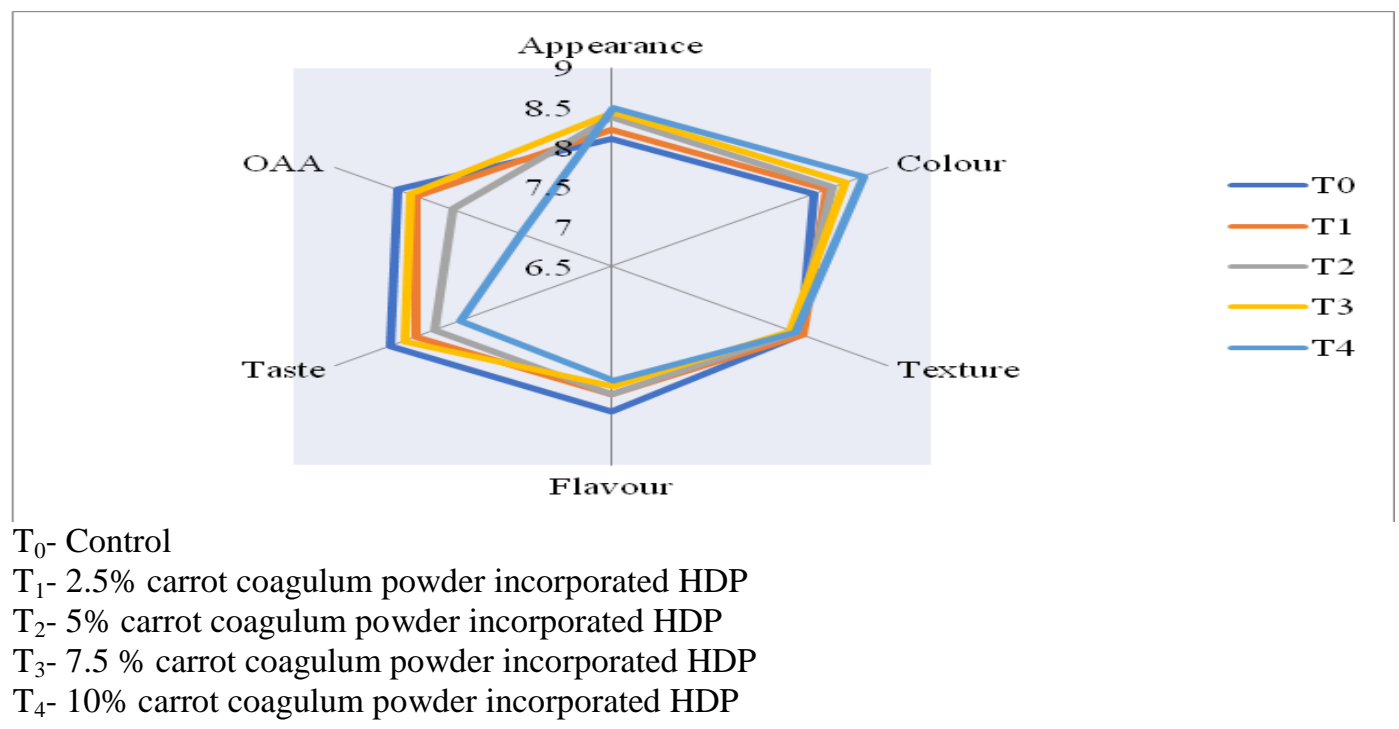

Nutritional composition of health drink powder with and without ECCP incorporation

\section{Proximate composition}

Based on the mean sensory score bestaccepted health drink powder incorporated with $7.5 \%$ of ECCP along with control without ECCP was analysed for proximate and results are presented in Table 3 . There was a significant difference for proximates between the control and health drink powder with ECCP incorporation except for fat and energy. High protein in HDP is mainly due to the incorporation of soy protein isolate, skimmed milk powder, and germinated green gram. Slightly lower protein values in ECCP incorporated health drink powder is due to dilution effect of ECCP. Protein and energy dense HDPs are considered helpful in eradication of malnutrition (Abrams et al., 2012).

Significantly higher moisture was found in control HDP compared to HDP incorporated with ECCP. Moisture content is important in maintaining food quality because increase in moisture facilitates the growth of microbes and ultimately destroys quality. El Wakeel (2007) reported that in case of dried materials, less than $10 \%$ of moisture content is considered as more proper for keeping quality of ingredients.

In this study, control scored higher for protein, and ash compare to HDP incorporated with ECCP. High values in control for protein and ash was mainly attributed to the presence of skimmed milk powder. Crude fibre, carbohydrates, and energy contents were higher in HDP incorporated with ECCP compared to control due to the addition of encapsulated carrot coagulum powder and was statistically significant. Encapsulated carrot coagulum powder (ECCP) contains maltodextrin as a carrier agent which further increase the carbohydrate and energy of HDP with ECCP incorporation. Control and health drink powder incorporated with ECCP showed a non-significant difference in fat and energy values. The present values were lower than the study conducted by Ahmad et al., (2013). He prepared three weaning food samples using different combination of rice flour, 
gram flour and papaya powder along with equal quantity of milk powder had protein content varying between 18.42-19.02, fat content 1.5-1.7, carbohydrate 17.24-17.58\% and ash content 3.5-3.8\%. Sule et al., (2019) incorporated carrot powder in wheat pasta. The significant reduction in crude protein with carrot powder incorporation could be attributed to the dilution effect from carrot powder, which is particularly lower in protein than other ingredients. Role of individual ingredients incorporated while formulating health drinks important in determining the outcome nutritive value (Salve et al., 2011).

\section{Water activity}

Water activity measures the available free water in food that is responsible for biochemical reactions and is an important index to determine microbial stability of food. In the present study, water activity in control HDP and ECCP incorporated HDP was 0.45 and 0.44. Low water activity inhibits the growth of microorganisms and other biochemical reactions. Normally food is considered microbiologically stable if the water activity is less than 0.6 (Quek et al., 2007; Solval et al., 2012). The present value is lower than 0.6 in both the HDPs.

\section{Total carotenoid content}

Carotenoids are the phytonutrients that impart a distinctive yellow, orange, and red color to various fruits and vegetables. It is the most potent precursor of vitamin A. There are more than 600 different types of carotenoids but only 40 of them are present in foods. Carrot is rich in carotenoids. Concerning the carotenoid content, lutein, lycopene, $\alpha$-carotene, and $\beta$ carotene are present in the highest quantity in carrots and are believed to have a role in maintaining bodily functions and preventing diseases. Carrot contains high amount of $\beta$ carotene. The main physiological function of $\beta$-carotene is as a very potent precursor of vitamin A (Grune et al., 2010). In this study, the total carotenoid content of HDP developed with ECCP incorporation was 1.24 $\mathrm{mg} / 100 \mathrm{~g}$ which was significantly higher than the HDP without incorporation of ECCP (0.60 $\mathrm{mg} / 100 \mathrm{~g})$. ECCP incorporation contributed to this significant increase. Total carotenoid content of obtained HDP incorporated with ECCP was higher that what was reported by Ravi et al., 2010. In their study, the Bcarotene value of weaning food incorporated with $20 \%$ of pumpkin powder was 110 $\mu \mathrm{g} / 100 \mathrm{~g}$.

\section{Mineral content}

Both the developed health drink powders had high mineral contents, but there was a significant difference between the drink powders (Table 4). Potassium, iron, sulphur, zinc, copper, and sodium were significantly higher in HDP with $7.5 \%$ of ECCP. Whereas other minerals such as calcium, phosphorus, magnesium, manganese content were significantly higher in control HDP. This was due to the substitution effect as evidenced by the nutritional composition of the individual ingredients. Higher calcium, phosphorus, magnesium, manganese content in control can be contributed to the original composition of skimmed milk powder.

Higher mineral levels especially iron, magnesium in the health drink powders could be due to the effect of malting on the millet. Malting has been reported to increase in vitro extractability and bioaccessibility of minerals such as calcium, iron, and zinc (Krishnan et al., 2012). Complimentary food prepared from malted millet, plantain, and soybean blends had sodium, potassium, magnesium, iron, the calcium content ranged from 2.80$3.180 .36-0.44,0.22-0.24,2.22-2.51,18.01-$ $25.10 \mathrm{mg} / 100 \mathrm{~g}$ (Bolarinwa et al., 2016). 
In this study a blend of the ingredients used in the study to prepare both health drink powders resulted in very balanced nutritional value, in terms of macro and micronutrients. Addition of carrot powder to prepared health drink powder had enhanced its nutritional value. Germination, mashing, and incorporation of carrot powder, successfully produced a high protein-energy food with acceptable nutritional properties.

In conclusion on the basis of sensory evaluation and nutrient analysis, the developed HDP incorporated with ECCPhad acceptable sensory values and contained high amount of macro and micronutrients. The nutrient analysis of the health drink powder highlighted that an increase in incorporation of ECCP increased the fibre, carbohydrate, energy, macro and micro minerals. The low moisture content and water activity are also a positive trait as these are associated with longer shelf life. Total carotenoid content of developed HDP was significantly higher than the HDP without ECCP incorporation and which can partly help to meet the Vitamin A requirement of vegetarian Indians. Overall, introducing encapsulated carrot coagulum powder into the health drink preparation contributed to good sensory characteristics but also increased its nutritional quality.

\section{References}

Abrams, S. A., Mushi, A., Griffin, I. J., Penni, D. and Allen, L., A. 2003. MultinutrientFortified Beverage Enhances the nutritional Status of Children in Botswana. The Journal of Nutrition, 133(6):834-1840.

Ahmad, S., Gupta, D. and Srivastava, A. 2012. Studies on Development, Quality Evaluation and Storage Stability of Weaning Food Prepared from Multipurpose Flour, Papaya Powder and Milk Powder. Journal of Food Processing \& Technology. 04.

Alamilla-Beltrán, L., Chanona-Pérez, J. J., Jiménez-Aparicio, A. R., Gutiérrez-López,
G. F. 2005. Description of morphological changes of particles along spray drying. J. Food Eng. 67: 179-184.

AOAC. 2005. Official methods of analysis. 15th Edn. Association of Official Analytical Chemist, Washington, D.C.

Augspole I., Rackejeva T., Kruma Z., Dimins F. 2014. Shredded carrots quality providing by treatment with Hydrogen peroxide. 9th Baltic Conference on "Food for Consumer Well - Being" FOODBALT. 150-154.

Biesalski, H. K., Bohles, H., Esterbauer, H., Furst, P., Gey, F., Hundsdorfer, G., Kasper, H., Sies, H., Weisburger, J. 1997. Antioxidant vitamins in prevention. Clinical Nutrition. 16(3):151-155.

Bolarinwa, I. F., Olajide, J. O., Oke, M. O., Olaniyan, S. A., Grace, F. O. 2016. Production and Quality Evaluation of Complementary Food from Malted Millet, Plantain and Soybean Blends. International Journal of Scientific \& Engineering Research. 5(664): 2229-5518.

Darshan, M.B. 2015. Encapsulation of $\beta$-carotene with natural polysaccharides using spray freeze drying technique. $\mathrm{Ph}$. D Thesis, Post-Harvest Technology, ICAR-Indian Agricultural Research Institute, New Delhi.

El Wakeel, M. A. 2007. Ultra Structure and Functional Properties of Some Dry Mixes of Food. M.Sc. Thesis, Faculty of Agriculture, Cairo: Ain Shams University.

Eneche, E. H. 1999. Biscuit-making potential of millet/pigeon pea flour blends. Plant Foods for Human Nutrition. 54, 21-27.

Ersus, S. and Yurdagel, U. 2007. Microencapsulation of anthocyanin pigments of black carrot (Daucus carota L.) by spray drier. Journal of Food Engineering. 80(3):805-812.

Farzana, T., Mohajan, S., Hossain, M. D. N. and Ahmed, M. M. 2017. Formulation of a Protein and Fibre Enriched Soy-Mushroom Health Drink Powder Compared to Locally Available Health Drink Powders. Mal. J. Nutr. 23(1): 129 - 138.

Griffith, L. D., Castell-Perez, M. E. and Griffith, M. E.1993. Effects of Blend and Processing Method on the nutritional quality of weaning foods made from select cereals and legumes. Cereal Chem. 75: 
105-112.

Grune, T., Lietz, G., Palou, A., Ross, C., Stahlguangweng, W. 2010. $\beta$-Carotene Is an Important Vitamin A Source for Humans. The Journal of Nutrition. 140(12): 2268-2285.

Gustavsson, J., Cederberg, C. and Sonesson, U. 2011. Global Food Losses and Food Waste - extent, causes and prevention. Food and Agricultural Organization of the United Nations (FAO).

Jiang, H. and Adhikari, B. 2013. Fruit and vegetable powders. In Handbook of Food Powders; Bhandari, B., Bansal, N., Zhang, M., Schuck, P., Eds.; Woodhead Publishing: Sawston, UK, pp. 532-552.

Kasale, K., Malagi, U. and Naik, K. R. 2019. Nutrient composition and antioxidant components of newer carrot germplasms. Pharma Innovation. 8 (1): 23-28.

Keding, G. B., Schneider, K. and Jordan, I. 2013. Production and processing of foods as core aspects of nutrition sensitive agriculture and sustainable diets. Food Security. 5(6):825-846.

Krishnan, R., Dharmaraj, U., Malleshi, N. G. 2012. Influence of decortication, popping and malting on bioaccessibility of calcium, iron and zinc in finger millet. LWT-Food Sci Technol. 48:169-74.

Quek, S. Y., Chok, N. K. and Swedlund, P. 2007. The physicochemical properties of spraydried watermelon powders. Chemical Engineering and Processing. 46(5):386392.

Ranganna, S. 1986. Handbook of analysis and quality control for fruits and vegetable products. 2nd ed. Tata Mc Graw-Hill Pub. Co. Ltd.,New Delhi. Pp: 1152.

Ravi, U., Menon, L., Ranjani, M. 2010. Nutritional, sensory and physical analysis of pumpkin flour incorporated into weaning mix. Malaysian journal of nutrition. 6:379- 387.

Salve, R. V., Mehrajfatema, Z. M., Kadam, M. L. and More, S. G. 2011. Formulation, Nutritional Evaluation and Storage Study of Supplementary Food (Panjiri). J. Food Process. Technol.2: 6.

Sarabandi, K., Jafari, S. M., Mahoonak, A. S. and Mohammadi, A. 2019. Application of gum Arabic and maltodextrin for encapsulation of eggplant peel extract as a natural antioxidant and color source. Int. J. of Bio. Macromolecules. 140: 59-68.

Simon, P. W. and Wolff, X. Y. 1987. Carotenes in typical and dark orange carrots. J. Agric. Food Chem. 35: 1017- 1022.

Solval, K. M., Sundararajan, S., Alfaro, L. and Sathivel, S. 2012. Development of cantaloupe (Cucumis melo) juice powders using spray drying technology.LWT - Food Science and Technology. 46(1):287-293.

Stoll, T., Schweiggert, U., Schieber, A. and Carle, R. 2003. Process for the recovery of a carotene-rich functional food ingredient from carrot pomace by enzymatic liquefaction. Inn. Food Sc. and Emerging Tech., 4: 415-423.

Sule, S., Oneh, A. J., Agba, I. M. 2019. Effect of carrot powder incorporation on the quality of pasta. MOJ Food Process Technol. 7(3):99-103.

Verma, A. and Singh, S. V. 2015. Spray Drying of Fruit and Vegetable Juices-A Review. Critical Reviews Food Sci. Nutr. 55(5): 701-719.

Wagner, L. A. and Warthesen, J. 1995. Stability of spray-dried encapsulated carrot carotenes. J. Food Sci. 60(5): 1048-1053.

\section{How to cite this article:}

Snehal Giri and Neena Joshi. 2020. Improvement of Micronutrient Content in Health Drink Powder with Incorporation of Encapsulated Carrot Coagulum Powder. Int.J.Curr.Microbiol.App.Sci. 9(12): 2629-2639. doi: https://doi.org/10.20546/ijcmas.2020.912.311 